College in 1883, he established the School of Library Economy, the first institution in the United States for the training of librarians. His welcoming of women pupils met with much disapproval, as did his questionnaire concerning their height, weight, and colour of hair and eyes, and his request for a photograph. From 1889 until 1906 he was director of the New York State Library, and he inaugurated a system of travelling libraries and picture collections: A man of boundless enthusiasm and energy, Dewey promoted the use of the metric system and was keenly inter. ested in spelling reform. In his long and useful life this great library pioneer succeeded in making many friends and also many enemies. He died in Florida on December 26, 1931 .

\section{The Coal Industry of Great Britain}

THE study of the coal industry carried out by the Acton Society Trust and published under the title "The Extent of Centralization" merits the attention of a wider field than those directly connected with the industry, for it may be said that the economy of Great Britain as a whole hinges upon coal, the most important of its natural resources. Apart from the discussion of the position of the technical specialists and the use made of them-a problem which is particularly acute in the coal industry, for reasons indicated in this study, and which is the main source of complaints of over-centralization made by men within the coal industry - the report is important as providing strong evidence against the desirability of rapid and sweeping changes by legislation or otherwise. It points out that improvements are most likely to be achieved gradually; the problems are cssentially those of human relations, and what is required appears to be a series of small practical improvements which in the aggregate will eventually change the whole atmosphere of the industry. The inquiry gives a: clear picture of the organization of the industry and of the system of technical and functional control in use. It indicates the impossibility of carrying out a large programme of reequipment. and redevelopinent on a national scale with the fullest economy without some interference with the free judgment and initiative of local government. Arrangements for achieving these ends are largely responsible for the sense of frustration which exists at several levels of the industry and for many complaints of over-centralization. Some research may well be required in order that all such problems may be solved; and the difficult one of the status of the colliery manager, the wider implications of which are discussed elsewhere, will only be fully solved when by a process of education a more highly trained type of manager, alert enough to seek and use the best technical advice available, is readily obtainable.

\section{Antiquity of the Australian Aborigines}

Ar the Brisbane meeting of the Australian and Now Zealand Association for the Advancement of Science, Mr. Edmund D. Gill, palæontologist in the National Museum of Victoria, gave an address on new evidence for the antiquity of man in Australia. He pointed out that Sir Richard Owen described the extinct marsupial Thylacoleo from bones collected by an early settler, William Adeney, from the shore of Lake Colongulac (=Timboon), Western Victoria, beside which he lived. For more than a century this has been the classic locality in Victoria for extinct giant marsupials, Diprotodon, Procoptodon, etc., being also described from here by Owen, McCoy and others. However, it has not been known previously from what bed these fossils came, but recently this was discovered and fossils collected therefrom. A dingo jaw and a carved bone (the Colongulac Bone of earlier authors), evidences of human occupation, were also collected by Adeney, and are in the National Museum, Melbourne. The fossils from this bed are remanié, being derived from a still earlier bed. An unusual matrix and the type of preservation made it easy to recognize that the collections in the Museum from Lake Colongulac came from this horizon. Since the extinct marsupial fossils were embedded, the local volcanoes have laid down an ash-spread, and a lake has cut back the resultant tuff for a great distance so as to form cliffs in it. After that came a comparatively arid period when the lake dried up, and dunes of loess more than $50 \mathrm{ft}$. high were built from the desiccated lake floor. In this loess a fossil aborigine was found. Since the dune-building phase, there has been a pluvial period when the lake returned, cutting cliffs $25-30 \mathrm{ft}$. high in the loess; also a highlevel alluvium (now incised) was deposited in the valleys of creeks entering Lake Colongulac (consequent type). The loess is considered to belong to the Mid-Holocene Arid Period and the tuff to early Holocene. The cycles of sedimentation and erosion affecting the fossil bones thus carry back into the Pleistocene. Hence there is evidence for Late Pleistocene and Middle Holocene human occupation of this area.

\section{British Bulletin of Spectroscopy}

A NEW venture in the literature of spectroscopy started this September with the first number of the British Bulletin of Spectroscopy. It is in the form of a four-page news sheet with notices of forthcoming events, reports of various meetings in Britain and overseas, and notes and comments on recent publications and on new experimental techniques, including a summary of recent progress on applied spectroscopy at the British Iron and Steel Research Association. The Bulletin is in two sections: emission spectroscopy, edited by K. Dixon and W. Ramsden; and molecular spectroscopy, edited by G. H. Beavan and W. C. Price. It has been published with the co-operation of the Industrial Spectroscopy Group of the Institute of Physics, the Photoelectric Spectroscopy Group, the Infra-Red Discussion Group and the Physical Methods Group of the Society of Public Analysts and Other Analytical Chemists. It is hoped that the Bulletin will mark a step towards closer co-ordination of the several spectroscopic groups in Great Britain. In the foreword, by S. D. Steele, the need is stressed for some publication to cover the many small developments in experimental technique which often fail to find their way into the major scientific journals. It is also hoped that the Bulletin may become a useful medium for expressing views by correspondence, which will be welcomed. It is published independently and is available to all interested at $5 \mathrm{~s}$. a year, post free, from the honorary treasurer, W. H. Storey, Unicam Instruments (Cambridge), Ltd., Arbury Road, Cam. bridge.

\section{The Fair Isle Bird Observatory}

THE second annual report of the Fair Isle Bird Observatory Trust is, like the first, a record of sound work well done. During 1950 active field-work was carried out for a period of twenty-eight weeks, the 